\title{
LA PRUEBA TESTIFICAL Y ALGUNAS CIRCUNSTANCIAS MODIFICATIVAS DE LA RESPONSABILIDAD PENAL EN ROMA Y EN EL ANTIGUO RÉGIMEN
}

\author{
Luis Rodríguez Ennes*
}

\section{Resumen}

La prueba testifical constituyó el medio probatorio prevalente en el proceso romano arcaico y clásico. Con el tiempo, debido a influjos orientales, los testimonios dejaron de ser solventes. Esta desconfianza se mantiene durante todo el Antiguo Régimen y pervive en la España de hoy. Se analiza también cómo perviven hasta los códigos penales modernos las concepciones romanas respecto de algunas circunstancias modificativas de la responsabilidad penal.

\section{Palabras clave}

Testes. Falso testimonio. Prueba testifical. Edad penal.

\section{WITNESS TESTING AND SOME MODIFYING CIRCUMSTANCES OF PENAL RESPONSI- BILITY IN ROME AND IN THE OLD REGIME}

\section{Abstract}

Witness testing constituted the average probationary prevalent in archaic and classical Roman process. Eventually, due to oriental influences, the testimonies left solvent. This distrust is maintained throughout the old regime and survives in the Spain of today. The Roman conceptions are analyzed also like keeps up to the penal modern codes respect of some modifying circumstances of the penal responsibility.

Keywords

Testes. Witness proof. Perjury. Penal age.

\section{INTRODUCCIÓN}

Los testigos constituyen el medio de prueba prevalente en Derecho Romano arcaico y clásico, debido, sobre todo a su veneración por la fides, por la fidelidad a la palabra dada. Con todo, como consecuencia del desplazamiento del centro de gravedad del Imperio hacia Oriente va perdiendo progresivamente importancia en beneficio de los documentos públicos. Se analizan estos

\footnotetext{
* Catedrático de Derecho Romano - Universidad de Vigo (España). Reales Academias de Juris-
} prudencia y Legislación y de la Historia. E-mail: ennes@uvigo.es 
extremos y se estudia también la evolución histórica de otras circunstancias modificativas de la responsabilidad penal.

\section{PRUEBA TESTIFICAL Y FALSO TESTIMONIO EN ROMA Y A FINALES DEL ANTIGUO RÉGIMEN}

En la época antigua y por la decisiva influencia atribuida a la fides el testimonio oral de los testigos constituía el medio de prueba más apreciado ${ }^{1}$, por no decir el único ${ }^{2}$. Según una praxis de larga tradición, los testigos, previo juramento de decir la verdad-iurati testimonium dicunt- deponían oralmente ante el iudex lo que hubieran visto u oído por sí mismos. También sabemos por la Ley de las XII Tablas que estaba permitido al litigante que se hubiera visto defraudado por su testigo realizar una extraña vindicta sacral consistente en acudir durante tres días delante de la casa del fallido testigo, realizando allí una especie de conjuro verbal -obvagulare- ${ }^{3}$. Esta suerte de maldición claramente de origen y contenido mágico-religioso y sin duda antiquísimo, irá perdiendo poco a poco con la secularización del ordenamiento aquel su primer sentido sacro transformándose en un mero instrumento de reprobación social y pública ${ }^{4}$. Primitivamente el falso testimonio era castigado arrojando al culpable por la roca Tarpeya ${ }^{5}$. En principio no existió ninguna limitación con relación al número de testigos que podían presentar las partes, si bien algunas constituciones imperiales, según parece desprenderse de un pasaje de Arcadio Carisio (D. 22, 5, 1, 2) concedieron a los propios jueces la posibilidad de limitar el número de los testigos seguramente con el fin de evitar los abusos y la excesiva duración del proceso.

Con el tiempo, sin embargo, llegaron a admitirse testimonios jurados o no jurados, prestados extrajudicialmente y reflejados en documentos aunque posiblemente nunca tuvieron excesivo valor probatorio. Este decrecimiento,

1 U. ÁlVAREZ, Curso de Derecho Romano, vol. I, Madrid, 1955, p. 431; J. L. MURGA GENER, Derecho Romano Clásico, vol. II, El proceso, Zaragoza, 1980, p. 140.

2 Es curiosa la preferencia que se otorga a la prueba testifical frente a la documental cuando, por influjos provinciales, va admitiéndose esta última, que no logra vencer una general desconfianza; así dice Cicerón en Pro Archias, 4, 8: Es ridiculum... cum habeas amplissimi viri religionem integerrimi municipio ius iurandum fidemgne ea, quae depravari nullo modo possunt repudiare, tabulas quas idem dicis solere corrumpi, desiderare. Sobre la prevalencia de la prueba testifical, vid., A. FERNÁNDEZ DE BUJÁN, "Testigos y documentos en la práctica negocial y judicial romana", en IVRA 54 (2003, publ.l en 2006) p. 21 ss.

3 XII Tab. II, 3: Cui testimonium defuerit, in tertiis diebus ob portum obvagulatum ito. Para el significado de portum y obvagulatio, vid. Fest. de verborum significatu, ed. Lindsay, Leipzig, 1913, p. 262-263.

4 Cfr. T. MOMMSEN, Rec. A Escher, "De testium ratione quae Romae Ciceronis aetate obtinuit", en Juristische Schriften 3 (Berlín-Dublín-Zurich, 1965) p. 407.

5 La referencia proviene de Aulo Gelio, Noctes Atticae, 20, 1, 53: An putas, Favorine, si non illa etiam ex Duodecim Tabulis de testimoniis falsis poena abolevisset et si nune quoque, ut anteza, qui falsum testimonium dixisse convictus esset, e saxo Tarpeio deiceretur, mentituros fuisse pro testimonio tam multos quam videmus.

v. 35.2, jul./dez. 2015 
además de a influjos orientales que destacaron el valor de la prueba escrita y del documento en general, se debió también a una gradual desconfianza hacia las declaraciones de los testigos, como nos testimonian abundantemente las fuentes literarias ${ }^{6}$. Hasta tal punto estaba extendida y era frecuente esta práctica, que uno de los mayores elogios que se podían dedicar a una persona era afirmar que constituía un "testigo solvente" ${ }^{\prime \prime}$. No tiene nada de extraño, pues, que en el Bajo Imperio numerosas disposiciones revelen esta hostilidad a la prueba testifical regulando minuciosamente la valoración que el juez debe otorgar a tal medio probatorio ${ }^{8}$.

Tradicionalmente el delito de falso testimonio fue reprimido en cuanto que perjurio y sacrilegio, al constituir una violación del juramento prestado, carácter que ostentó en el Derecho imperial romano, en nuestras Partidas y que todavía conserva, siquiera de nombre en las legislaciones germánicas y anglosajonas ${ }^{9}$. A esta sanción sacral alude el Padre Feijoo con su incomparable pluma:

Notables palabras las de Dios a Moisés, al capítulo nono del Deuteronomio, hablando del testigo falso: Non miseraberis eius, le dice: No Moisés, no te apiades, no te compadezcas, no tengas misericordia con él. Rígido parece el decreto. Rígido sí; pero preciso. Con el testigo falso toda ha de ser rigor, nada clemencia: Non miseraberis eius ${ }^{10}$.

6 Isid. Orig. 18, 15, 10 afirma que tal conducta podía consistir, bien en comprometerse el testigo a prestar falso testimonio, o bien a guardar silencio sobre la verdad: Duobus autem modis testes delinquunt: quum aut falsa promunt, aut vera silentio obtegunt. Esta clasificación tiene raíces mucho más antiguas pues Aulo Gelio la pone también en boca de Catón quien le reprochaba al tribuno de la plebe M. Celio vender a bajo precio no sólo sus palabras, sino también su silencio -non loquendi tantum, verum etiam tacendi- (Gel. Noctes Atticae 1, 15, 10). En cualquier caso, ya fuera de un modo activo o pasivo tales conductas se encontraban muy extendidas en la praxis judicial cotidiana (Juv. Sat. 14, 216-219: falsus erit testis y, como ya denunciaba con anterioridad Cicerón: falsis testes, pro Lig. 10, 30; testes in hunc et accusatores huiusse pecunia comparant, pro Ros. 11, 30; saductiones testiu, pro Mur 24, 39; instruit testis, pro Cluent. 6, 18; pecunia testibus deset, ibid. 67, 192. Numeroso acopio de referencias literarias en,: C. GUTIÉRREZ GARCÍA,- J. A. MARTÍNEZ VELA, "La prueba testifical en las fuentes literarias", en La prueba y medios de prueba de Roma al Derecho moderno, Armando Torrent (ed.), Madrid, 2000, p. 339 ss.

7 ...Seu centurio seu praefectus incorruptum facti testem habebat (cfr. Tac. Agricola, 22, 4).

8 El testimonio de un solo testigo carece de valor probatorio, cualquiera que sea la calidad de la persona que lo preste y la credibilidad que merezca: C. Iust. 4, 20, 9 de ahí procede el viejo y conocido aforismo: testis unus, testis nullus que tan diferente desarrollo va a experimentar-como tendremos ocasión de ver- en el antiguo Derecho castellano. En los pleitos seguidos contra cristianos no se debe otorgar fe alguna a los testimonios prestados por herejes y judíos (C. Iust. 1, $5,21)$. Se restringe la obligación de prestar juramento a los testigos pertenecientes a las clases inferiores (Ibid. 40, 20,9) y se admite la aplicación de la tortura a los sospechosos de no decir verdad (Nov. 90, 1).

9 En la legislación punitiva hispana el nombre de "perjurio" figuró por última vez en el Código de 1822, desapareciendo en el de 1848.

${ }^{10}$ Discurso undécimo: "Balanza de Astrea", [43], en Teatro Crítico Universal, vol. III, Madrid, 1726. 
Norma básica de los doctores del Derecho común es que bastaba el testimonio coincidente de dos testigos para hacer prueba plena de cualquier delito por atrocísimo que fuera. Y dado que el juez había de valorar previamente la prueba con arreglo al criterio dominante en Derecho - prueba tasada o reglada- el acuerdo de dos testigos contra alguien le obligaba a condenarlo ${ }^{11}$. Pero lo peor era que, en contravención del principio romano testis unus testis nullus $^{12}$, el testimonio de un solo testigo era legalmente suficiente para dar tormento $^{13}$. Es obvio que las normas del antiguo Derecho castellano castigaban con severidad el falso testimonio ${ }^{14}$ pero al igual que acaece en nuestros días, el precepto punitivo quedaba en pura letra muerta. A esta manifiesta impunidad se refiere Feijoo:

Ninguna de estas penas me horroriza, por contemplar cuán necesario es en esta materia el rigor. Pero la más justa y razonable, al fin como dictada por boca divina, fue la del Talión, que Dios estableció en el pueblo de Israel. Esta misma recomiendan varios textos del Derecho civil. En España tuvo su uso por las Leyes de Toro $^{15}$. Más últimamente por no ser adaptable a todos los casos, el Señor Felipe II, dejándola en su vigor para las causas de sentencia capital, en que el testigo debe ser siempre castigado con la misma pena correspondiente al delito que falsamente asevera, constituyó para todos los demás casos la pena de vergüenza pública y galeras perpetuas ${ }^{16}$. Justísimo castigo ¿Pero cuándo se ejecuta? No sé si en la prolija carrera de mi edad le he visto aplicar alguna $v e z^{17}$. Lo que comúnmente sucede es que al tiempo de votar entra intempestivamente la piedad en la Sala, y a contemplación de esta serenísima Señora, en vez de vergüenza pública y galeras perpetuas, se decreta una multa pecuniaria ${ }^{18}$.

${ }^{11}$ ANTONIO GÓMEZ, Variae resolutionis, iuris civilis, communis, et regii, tomis tribus distinetae, vol. III, Madrid, 1780 p. 245 y las numerosísimas citas de doctores allí incluídas.

${ }^{12}$ Vid. nt. 8

${ }^{13}$ P. VII, 30, 3: "o seyendole probado por un testigo que sea de creer (...) puede lo mandar a tormentar el judgador". Gregorio López, en su glosa ad h. $t$. escribe: quando testis deponit de visu: nam alias iudicium debet probari per duos testes.

${ }^{14}$ P. III, 11, 26: bajo la rúbrica "Que pena merece quien jura mentira" se dispone: "E si por su testimonio mentiroso, o lisiado, que reciba el mismo otra tal pena". Part. III, 16, 42: "Pena muy grande merecen los testigos que a sabiendas dan falso testimonio contra otros o que encubren la verdad por mal querencia que han contra algunos".

${ }^{15}$ El Padre Maestro tenía cabal conocimiento de la Ley 83 de Toro, en cuyo tenor literal: "Quando se provare que algún testigo depuso falsamente contra alguna persona o personas en alguna causa criminal (...) le sea dada la misma pena en su persona y bienes como se le deviera dar aquel ó aquellos".

${ }^{16}$ Feijoo trae a colación la Ley de Felipe II de 1566, recogida en NR, VIII, 17, 1.

${ }^{17}$ La cursiva es nuestra. De ahí que ante tamaña impunidad era muy elevado el número de personas, que pagándoselo, juran en cualquier cosa que les piden.

${ }^{18}$ FEIJOO, F. B. J., loc. cit. en nt. 10 [42] 
Otra de las causas de la falibilidad de la prueba testifical descansaba en el quebrantamiento del principio de inmediación a la hora de practicarla. En principio en la actuación del juez entraba el requisito de inmediación, en cuya virtud era él personalmente quien debía recibir la prueba testifical dentro de la sede judicial. Pero, de la misma forma que hoy ocurre, la aglomeración de pruebas originó el desentendimiento de los jueces de su práctica directa, salvo casos de muy notoria importancia. Quedaban relegadas a los escribanos, a los auxiliares de éstos y aún a otro personal no judicial de los tribunales de las Audiencias, fueron regulando las obligaciones de los jueces y miembros de los tribunales en la recepción de las pruebas ${ }^{19}$. ¿Hasta qué punto llegó el cumplimiento de estas obligaciones por los jueces? Lo normal debió ser el incumplimiento estricto de la normativa, de la misma forma que hoy se sigue incumpliendo en los juzgados. A esta mala praxis multisecular alude Feijoo con su inimitable estilo:

Los Escribanos tienen mil modos de dañar. Raro hay tan lerdo, que dé lugar a que le cojan en falsedad notoria. Pero lo que se ve es, que todo el mundo, está persuadido a que en cualesquiera causa, que civil, que criminal, es de suma importancia tener al Escribano de su parte. El modo de preguntar ladino, hace decir al que depone más, o menos de lo que sabe. La introducción de una voz que parece inútil, o de pura formalidad al formar el proceso,

${ }^{19}$ Así, en las Ordenanzas de la Real Academia del Reyno de Galicia (en lo sucesivo ORGA) de 1769 se establece en I, 3, 19: "En las causas graves y de calidad los Alcaldes Mayores tomen por sus personas las confesiones a los reos, y asimismo examinen los testigos, sin cometer lo uno, ni lo otro a los Escrivanos de asiento, para que así mas bien se averigue la verdad". Cito por la edición impresa en la ciudad de La Coruña por Antonio Fraiz. Año de 1679, pero esta edición es muy disentida, M.MURGUÍA, en su Diccionario de Escritores Gallegos, Vigo, 1862, p. 19-20 así lo afirma y el P. ATANASIO LÓPEZ en La imprenta en Galicia. Siglos XVI a XVIII, Madrid, 1953, p. 145-146 se ratifica en la sospecha. C. MARTINEZ-BARBEITO, en su El "auto gallego" en los tratadistas y en la práctica forense, A Coruña, 1984, p. 38-39 dice: “Ocurría, y abundan los ejemplos, que algunas veces convenía por razones de seguridad, de prestigio y asín de halago, fingir que se imprimía un libro donde en realidad no se había impreso. Unas veces, porque el libro se imprimía clandestinamente y había que burlar la vigilancia de la autoridad confundiéndola; otras veces porque, como en este caso, podría agradar a la Audiencia que sus ordenanzas aparecieran impresas en la capital de su demarcación" y concluye: "No existiendo ninguna prueba de que haya habido imprenta en La Coruña hasta 1806, yo me inclino a creer que la edición es compotelana y no coruñesa". Con todo, este aserto final se contradice con lo que señala E. CARRE ALDAO. "Interin no contemos con otras pruebas, tenemos que concretarnos a señalar la fecha de 1679 como la del primer libro que se conoce impreso en La Coruña por Antonio Frayz (...) nos inclinamos a creer que se hubiera trasladado con alguna anterioridad a esta última ciudad, aunque volviese luego a Compostela, de no tener establecimiento en los dos lugares, pues aparece con fecha igual y posterior a la de La Coruña en libros impresos en Santiago" [cfr. "El primer libro impreso en La Coruña", en BRAG 1 (1906-1907) p. 36-39=A imprenta en Galicia (A Coruña, 1991) p. 9 ss.]. Amplias referencias al contenido de las Ordenanzas en L. RODRÍGUEZ ENNES, Aproximación a la Historia Jurídica de Galicia, Santiago de Compostela, 1999, p. 80 ss.; ID., Estilo de la Real Audiencia de Galicia, en AHDE, LXIX 1996, p. 485 ss. 
hace después gran eco en la Sala: la substitución de otra, que parece equivalente a la que dijo el testigo, altera tal vez todo el fondo del hecho ${ }^{20}$.

Al existir entonces las mismas condiciones y causas que en la actualidad -la aglomeración de trabajo, lo rutinario y desesperante de la mayoría de las probanzas, la dispersión en el tiempo de este tipo de pruebas, que requería que el juez tuviese en la mente en todo momento la totalidad de los pleitoslas soluciones, prácticamente, serían las mismas de ahora: dejar a un lado la norma y encauzar de la mejor forma posible la actividad judicial, en la manera más operativa que se pudiese. Si hoy la intervención judicial se suele limitar a recibir por sí las declaraciones en las causas más graves, o de los testigos más decisivos, limitándose a ratificar el resto, realizadas ante el funcionario subalterno, lo mismo parece haber ocurrido con el juez del Antiguo Régimen ${ }^{21}$; la irrisoria pena pecuniaria -que se imponía raramente-coadyuvaba sin duda al incumplimiento del deber de inmediación, de qué que Feijoo propugnase un endurecimiento de las sanciones:

Todos los ojos de Argos, colocados en cada Togado, son pocos para observar las innumerables falacias de un Notario infiel. Pero a proporción de la dificultad del conocimiento, se debe aumentar el rigor. De mil infieles sólo será descubierto uno; y es menester proceder con tanta severidad con este uno, que en el escarmiente todo el resto de los mil. Hágase tener el castigo por grande, ya que no puede por frecuente $\mathrm{e}^{22}$.

La legislación decimonónica mantuvo y aún endureció los mismos criterios. No podía ser menos en una normativa en que los derechos de los ciudadanos cobraban significado y en que la justicia, como institución imparcial al servicio de la sociedad requería un exquisito cumplimiento de las garantías procesales. De esta forma, el Reglamento Provincial de la Administración de Justicia, en su artículo 8 estipuló que "en toda causa criminal, así los procesados como los testigos serán precisamente juramentados y examinados por el juez de la causa y ante el escribano de ellas". Sin embargo, la situación había tomado un rumbo difícil de cambiar. Y así continúa...

${ }^{20}$ FEIJOO, F. B. J., loc. cit en nt. 10 [47]. Coincide el sabio de Casdemiro con la opinión de CASTILLO DE BOVADILLA, buen conocedor de la mecánica y estilo de los juzgados: "ay escribanos que tiene las plumas venales y pervierten la verdad, o son tan necios o malignos que no representan al testigo para saber quien fue el agresor" [cfr. Política para Corregidores y señores de vasallos, vol. II, Amberes, 1750, p. 262, II, p. 262]. Lo peor era que, en muchas ocasiones, los que tomaban declaración a los testigos eran los escribientes de los escribanos "siendo los tales escribientes moços y pobres y de poca confianza y que con facilidad las partes los puedan corromper", como denuncian las Cortes de Madrid de 1571.

${ }^{21}$ R- ROLDÁN VERDEJO, Los Jueces de la Monarquía Absoluta (La Laguna, 1989) p. 279 ss.

${ }^{22}$ F. B. J. FEIJOO, loc. cit. en nt. 10 
Sin que sirva de disculpa a esta viciada praxis procedimental, es indudable que la ingente masa de materiales que tenían que manejar los operadores jurídicos, constituía un acicate a la confusión negligente o dolosa a la hora de concretar la norma aplicable o invocar la doctrina legal pertinente. El modelo que regía en el Antiguo Régimen estaba formado por estratificaciones de material jurídico heterogéneo (costumbres locales, fueros municipales, estatutos locales y corporativos, decisiones judiciales, edictos de los soberanos, leyes feudales, canónicas y romanas, opiniones doctrinales e interpretaciones de la jurisprudencia) que reflejaban el particularismo institucional de una sociedad basada en el carácter autónomo de los ordenamientos jurídicos y la diferenciación estamental. Las recopilaciones legislativas realizadas en los siglos XVI y XVII no habían logrado modificar la situación, que en el umbral del siglo XVIII, seguía caracterizándose por un desorden y una contradicción extremos, causa de perpetua incertidumbre en el derecho y de un grave malestar en la justicia y contrastaba ahora fuertemente con las tendencias del Estado moderno a la centralización y la igualación ${ }^{23}$.

Por otra parte, el derecho nacional, desde fines de la Edad Media, se hallaba relegado a un segundo plano en las Universidades y tribunales del reino en beneficio del derecho común romano-canónico, aumentando su retracción la dificultad de su conocimiento disperso como se hallaba en códigos y leyes de diferente época y autoridad ${ }^{24}$. Otro factor contrario a la doctrina del viejo ius commune era intrínseco a la misma y consistía en su propia rutina ${ }^{25}$. Falta de renovación, la doctrina romanista permanecía lastrada por su rancio e irreversible envejecimiento. No es de extrañar, en consecuencia, que a mediados de siglo se posea conciencia clara de que los tesoros de la interpretación jurídica se habían tornado en gruesa carga para los juristas. Los libros de los intérpretes son áridos, dificultosos de leer, las glosas o los tratados sobre una materia -entre las que se entrelazaban otras muchas- las decisiones o consejos explican oscuramente las cosas e introduzcan no pocos errores por la variedad

${ }^{23}$ Diccionario Histórico de la Ilustración, Ferrone y Roche (eds.), Madrid, 1998, p. 124.

${ }^{24}$ En 1765 sale la primera edición de Juan Francisco DE CASTRO, Discursos críticos sobre las leyes y sus intérpretes, en la que condena el exceso en el Derecho romano como uno de los enemigos capitales de la práctica: "Entre la inmensidad de leyes civiles y canónicas, entre el inexplicable número e inagotable fluxión de buenos y malos libros nacionales o extranjeros, opiniones del mismo dictado y patria, escritas y no escritas costumbres, sumergida toda humana capacidad, le hace detestar una profesión en que nada hay apenas cierto y seguro, y en el que más alcanza sólo llega, después de encontrarse en los últimos períodos de su vida, destruida su salud con tantos y tan penosas tareas, o poder más que otros por propia experiencia certificar esta verdad y asegurar lo inextricable de este laberinto" [f. I, p. III, cito por la segunda edición (Madrid, 1821)].

${ }^{25}$ Cfr., a este respecto, L. RODRÍGUEZ ENNES, "El antirromanismo ilustrado", en SDHI LXXIV (2008) p. 663 ss., con abundante literatura. 
de opiniones que traen; otros incluyen grandes listas de doctores para aumentar la confusión...

A los abusos forenses que genera este mundo extensísimo, farragoso y complicado se refiere, sin ambages, Feijoo, que manifiesta su honda preocupación por la proclividad de letrados, procuradores y escribanos a emitir informes falsos:

Por tanto mi sentir es, que no haya indulgencia o remisión alguna, ni con el Abogado que supone citas, o doctrinas (dejando a la prudencia los casos en que esto se pueda atribuir a equivocación, o falta de memoria); ni con el Escribano, o Recetor, que dolosamente colorea los dichos de los testigos; ni con el Relator, que suprime cláusulas. Semejantes atentados, si se encamina su contrariedad a la virtud de la Justicia, tanta malicia como una deposición ${ }^{26}$.

Conspicuos contemporáneos de Feijoo van a abundar en la denuncia de este estado de cosas como el ya citado De Castro $^{27}$ o Medina y Flores ${ }^{28}$. Con todo, Sarmiento afronta una crítica mucho más radical que su sabio maestro. En efecto, es él quien señala el quid de la cuestión: "Las Leyes deben ser puras, sin comentos, ni pegotes, ni fárragos ${ }^{29}$ y abunda en la necesidad de denunciar los excesos interpretativos a los que había conducido la inflación comentarista

${ }^{26}$ F. B. J FEIJOO, loc. cit. en nt. 10 [45].

${ }^{27}$ F. DE CASTRO, escribe: “El trabajo de nuestros intérpretes es inmenso. Entrando cualquiera en casa de un abogado que, o sea verdaderamente exacto en su empleo, o sólo tenga el gusto de hacer de la ostentación, viendo las paredes de su estudio cubiertas de libros, se confirmará en esta verdad, y mucho más si se reserva la reflexión de que allí falta la mayor parte de estos escritos (...) Esta multitud crece con los siglos, cada año produce nuevos intérpretes y nuevos escritores (...) No sólo los escritores españoles ocupan nuestras bibliotecas jurídicas, sino que también en ellas los autores extranjeros tienen un muy distinguido lugar y con ellos enriquecemos nuestra Jurisprudencia. Con la ocasión de que nos exponen el derecho romano y canónico, los leemos, citamos, y de ellos nos valemos para patrocinar nuestras causas en asuntos diferentes, sin advertir la confusión en que nos envuelven y los engaños que en su lectura recibimos" [Cfr. Discursos, cit., I, p. 201 ss.).

${ }^{28}$ MEDINA Y FLORES, Representación para promover el estudio de el derecho español y facilitar su observancia (1744) editada de nuevo por F. Canella Secades, "El Derecho Español en 1744" en RGLJ 52 (1878) p. 353 ss.: "Pero por el siglo decimocuarto introducido en la jurisprudencia el método escolástico, se hicieron sus profesores linces en las disputas y topos para las resoluciones, quedaron más sutiles, pero menos sólidos; abríanse ya los Digestos y se escudriñaban sus leyes, no para retener lo que disponen, sino es para ver en lo que se contradicen; desde entonces más se aprecia el hallazgo de una antinomia que el de cien verdades. Trocaron lo útil por lo deleitable y la doctrina por el lucimiento, y como estos avisos se hicieron naturaleza con el largo uso, quedaron tanto más perjudiciales cuanto más desconocidos".

29 F. M. SARMIENTO, Obra de Seiscientos Sesenta Pliegos que trata de Historia Natural y de todo género de Erudiciba con motivo de un papel que parece se había publicado por los Abogados de La Coruña contra los foros y tierras que poseen en Galicia los benedictinos, Col. Dávila, Biblioteca Nacional, ms. 20.392, fol. 2495 .

v. 35.2 , jul./dez. 2015 
y que, en realidad, fueron los causantes de que el antirromanismo se eriegiese como una de las banderas programáticas de la Ilustración ${ }^{30}$.

\section{ALGUNAS CIRCUNSTANCIAS MODIFICATIVAS DE LA RESPONSABILIDAD PENAL}

\subsection{Edad}

En el Derecho romano el elemento subjetivo del delito puede faltar por la temprana edad del autor del mismo. Ya en las XII Tablas se hacía distinción entre púberes e impúberes. Las leges iudiciorum publicorum ${ }^{31}$, exigían que el agente fuese pubes para aplicarle la pena y también el senadoconsulto silaniano excluía de sus sanciones a los servi impuberi ${ }^{32}$. Es muy conocida la enunciación general de Pomponio neque impuberem... capitalem fraudem videri admi$\operatorname{sisse}^{33}$.

Una gran influencia sobre toda esta materia debe atribuirse a Salvio Juliano quien discrimina plenamente los actos cometidos por el infans ${ }^{34}$. La infancia dura hasta que el niño habla correctamente, y su término debe fijarse caso por caso. Sobre este particular hay que hacer notar que no se atendía tanto al hecho material de que el niño supiera palabras como, al haber adquirido conciencia de su significado ${ }^{35}$. Justiniano, generalizando quizá alguna decisión anterior, estableció que se considerase infans a todo hombre que no hubiese cumplido todavía los siete años ${ }^{36}$. Durante este tiempo, el infante, puesto que carece de uso de razón, es incapaz de ejercer sus derechos, ni se hace responsable por sus acciones. Los impúberes infantia maiores, desde los siete años a los catorce en los varones y hasta los doce en las mujeres, se subdividen en infantiae proximi y pubertati proximi según su mayor o menor desarrollo de la inteligencia, fijándose la imputabilidad penal en torno a los nueve o diez años; en consecuencia, para los proximi infantiae se estableció la irresponsabilidad ${ }^{37}$. Paulo considera como inaplicable la pena del crimen falsi a los impúberes sin distinción, no reputándolos capaces del dolo específico requerido para este acto delictivo ${ }^{38}$.

${ }^{30} \mathrm{Ibid}$, fol. 247. La cita, muy amplia, está recogida en nuestro Fray Martín Sarmiento y el mundo del Derecho, Santiago de Compostela, 2005, p. 150,nt. 316.

31 D. $48,6,3,1$.

32 D. $29,5,14$.

33 D. $21,1,23,2$.

34 H., BUHL, Salvius Julianus I, Heidelberg, 1886, p. 149 ss.

35 DAZA-RODRÍGUEZ ENNES, Instituciones de Derecho Privado Romano ${ }^{4}$ (Valencia, 2009) p. 42.

${ }^{36}$ D. $23,1,14$.

37 Ya en tiempos de Gayo, 3, 208: Plerisque placet, quia furtum ex adfecu consistiti, ita demum obligare eo criminare impuberem, si proximus pubertari sit et ob id intellegat se delinquere. A esta regla se refiere también D. 50, 17, 108 .

38 C. FERRINI, Diritto Penale Romano, Roma, 1976, p. 64. 
En las Partidas se establecen para "toller" (diez años y medio) o "menguar" (diecisiete años) la pena ${ }^{39}$ que no coinciden con las de otros textos legales. De modo que ni siquiera esta ley, la más general en este punto, ofrece un criterio sistemático ni una valoración utilizable en todo caso ${ }^{40}$. En los llamados "delitos de luxuria", estaban excusados de toda pena el varón menor de catorce años o la mujer menor de doce "porque no han entendimiento". En todos los demás delitos quedaba exento de pena el menor de diez años y medio ${ }^{41}$. Gregorio López recordaba en una de sus glosas que el derecho común distinguía en orden a este último límite entre varones y hembras, rigiendo para aquellos la edad mínima de diez años y medio y para éstas la de nueve años y medio $^{42}$ pero hacía ver que tal diferencia no había pasado a ninguna de las leyes de Partida ${ }^{43}$, llegando a proponer incluso el castigo del menor de tan temprana edad justificándolo sobre la base del aforismo canónico malitia suplet aetatis $^{44}$.

Esta sistemática del discernimiento fue práctica desarrollada e impuesta a lo largo del Medievo y la Edad Moderna y persistió casi por doquier hasta el pleno desarrollo de las jurisdicciones de menores y el nuevo sentido adoptado por su función eminentemente tutelar.

A esta doctrina punitiva se adscribe Feijoo:

Soy que esta razón no valga, sino que precisamente se regule la pena por la mayor malicia y reflexión con que se comete la culpa. Esa mayor reflexión no está adicta a determinada edad; aún cuando, según el curso ordinario, lo estuviese, se deberá hacer excepción en todos aquellos casos, en que la malicia se anticipa al plazo ordinario. Para contraer matrimonio es regla Canónica que la malicia suple a la edad ¿Por qué no la ha de suplir para padecer el establecido suplicio? ${ }^{45}$.

39 P. VII, 31, 8.

40 TOMÁS Y VALIENTE, El Derecho Penal, cit., p. 339.

41 P. I, 1, 21; VI, 19.4; VII, 21, 2, VII, 1, 9; VII, 9, 8; VII, 14, 17; VII, 7, 10 y VII, 31, 8.

42 El derecho común recogía así la opinión de Gayo, 3, 208.

43 GREGORIO LÓPEZ, "Glosa de diez años y medio" a P. VII, 1, 9. En su opinión era ésta una materia en la que las leyes fijaban los citados límites por presumir que por debajo de esas edades el impúber non sit dolo capax; pero si en algún caso concreto el juez creía que el menor de diez años y medio había actuado con dolo podía castigarlo arbitrariamente.

${ }^{44}$ La dureza de Gregorio López respecto a la infancia es evidente, pues nos refiere entre nostálgico, exagerado y malicioso, que lo que en la antigüedad sabían y hacían los hombres en punto a vicios a los quince años, hoy lo hacen los muchachos a los seis o siete [Ibid., loc. cit. en nt. anterior, donde escribe: “... quod antiquites sciebant et faciebant homines, circa vitia et fallatias in quidecim anno, faciunt nunc infantes in sexto vel septio anno..."]-

45 FEIJOO, Paradoja Séptima "La edad corta es mas favorecida de los Jueces, en las causas criminales, de lo que debería ser" [59] en TCU. El título no deja lugar a dudas del alineamiento del Padre Maestro con las tesis tradicionales de que maliti a suplet aetatis. 
Esta consideración se esfuerza con otra. Si la malicia de un joven es superior a la que corresponde a su corta edad, se debe tener, que llegando a edad más adulta, sea extraordinariamente excesiva. Luego dicta la razón que se arranque esta planta venenosa del terreno de la República, antes que pueda serle más nociva.

Y noto aquí, que a veces la mitigación de la pena, en atención a la corta edad del reo por accidente, suele aumentar su malicia. Un mozo de veinte años comete un delito, a quien corresponde pena capital; pero por el favor de la edad de conmuta la horca en seis, o siete años de galeras. ¿Y qué es enviarle a galeras, sino a colocarle en la mayor escuela de malicia que tiene el mundo? ¿Con quién trata en la galera, sino con unos consumados maestros de maldades, surtidos de industrias para cometer todo género de infamias? Tales son los que le acompañan en la fatiga del remo: con que cumplido el plazo, sale de la galera más perdida la vergüenza, más fortalecida la osadía y más instruida la astucia ${ }^{46}$.

La pretendida razón de ser de la sistemática del discernimiento -que Feijoo defiende sin ambages, como se infiere de la rúbrica de la Paradoja Séptima ${ }^{47}$ - era una arbitraria medición del grado de libertad de elección entre el bien y el mal coordinada con la responsabilidad; es decir, una entre el bien y el mal coordinada con la responsabilidad; es decir, una cuestión que ha quedado rebasada con los nuevos propósitos de corrección y defensa social, a la vez, que los modernos ordenamientos punitivos postulan. No obstante lo dicho, el procedimiento extremadamente rígido de la prefijación de una minoría de dad absoluta, cualquiera que sea, pues ello ha de variar con las costumbre y aún con las condiciones raciales y climatológicas del país, adolece del defecto de generalización, susceptible de grandes injusticias ${ }^{48}$. A nadie se le oculta el

46 Ibid. [60-61].

47 Vid. la nt. 45. Para un análisis crítico del criterio del discernimiento como fundamento de la inimputabilidad del menor vid.: A, MARTÍNEZ CRUZ, Los fundamentos de la capacidad de culpabilidad penal por razón de la edad, Granada, 2004, pp. 52 ss.

48 Baste, a título ejemplificativo, con traer a colación que al mayor de diez años y medio y menor de diecisiete, la P. VII, 31, 8 decía que debía menguársele la pena ordinaria. Pero en la práctica parece que se ampliaba el límite de los diecisiete años, pues cuenta ALONSO DE VILLADIEGO que al mayor de esa edad y menor de veinticinco -aunque no había precepto legal sobre ellolos jueces le solían aminorar la pena ordinaria [Cfr. Instrucción política y práctica judicial, Madrid, 1747 p. 73, núms. 162-163]. Y es seguro que tal práctica seguía viva en pleno dieciocho, pues FEIJOO opinaba en contra de ella afirmando que precisamente entre los dieciocho y los veinticinco se cometen muchos delitos (especialmente adulterios, estupros y homicidios en pelea) por ser entonces "más furiosa la concupiscencia y más violenta la ira", razón por la cual ha de ser "más fuerte la mano en el uso de la rienda" para detener y corregir esas pasiones en edad tan critica [cfr. TCU, VI, primero, quinta parte, p. 27 ss). Felipe V castigaba en 1734 al ladrón cortesano a pena de muerte si era mayor de diecisiete año sy si mayor de quince sin llegar a diecisiete, a doscientos azotes y diez años de galeras (cfr. N. R. VIII, 11, 7). Como se ve a través de estas 
preponderante papel de lo individual en estas materias de desarrollo psíquico, intelectual y hasta fisiológico, por lo que todo límite fijo ha de ser forzosamente una ficción. Explicable en el Derecho privado, de matiz predominantemente formalista, no lo es tanto en el penal, donde la individualización se estima como técnica judicial prevalente, por lo que el Juzgador pudiera determinar en cada caso cuando el agente es susceptible o no de imputabilidad, asesorado por los datos periciales, ni más ni menos que en las otras circunstancias de inimputabilidad, como la enajenación mental. Y aquí sí que surge como un egregio precursor de la nueva doctrina en punto a la aplicación individualizada de la pena, el pensamiento de Feijoo:

Por todo lo dicho me parece que esta materia no se debe ligar a la letra de la ley común, sino remitirse al arbitrio de los Jueces, los cuales considerando la edad, y capacidad del delincuente, la gravedad y circunstancias del delito, y mucho más que todo, el número de veces que ha pecado, pueden determinar la pena, que según buena razón corresponde. Bien sí, que algunos Jueces, aunque muy pocos, lo ejecutarán asíi ${ }^{49}$.

\subsection{Reincidencia}

Entre las circunstancias agravantes ocupa un puesto preeminente la reincidencia. Su etimología es clara, proviene de recidere, recaer, es, pues, la repetición de la actividad delictiva por parte de un mismo sujeto ${ }^{50}$. Sin embargo, en el lenguaje jurídico penal, dicho término presenta una acepción mucho más restringida, referida a la pluralidad de delitos mediando entre ellos sentencia condenatoria. El continuo aumento de la reincidencia y de la criminalidad profesional, que en todas partes se señala, prestan cada día mayor interés a esta cuestión. Así ha surgido la noción del "delincuente habitual”. Aún cuando este concepto fue elaborado principalmente por la doctrina y la legislación penal de la pasada centuria ya aparecen en el Derecho Romano nociones equivalentes como la consuetudo delinquendi $i^{51}$, que por costumbre forense determinaba

leyes, el tope de la mayoría de edad penal oscilaba entre los diecisiete y los veinte años, respetando siempre el de la edad mínima de los diez años y medio.

${ }^{49}$ FEIJOO, loc. cit. en nt. 45 [62]. Para MARTÍNEZ RISCO : "El cotejo no puede ser más elocuente y decisivo para comprender y afirmar que el $\mathrm{P}$. Maestro puede ser considerado como el precursor de esa moderna técnica punitiva que, entrañando una manifestación del arbitrio judicial más o menos puro, ha cristalizado en norma positiva general, universalmente formulada, para la determinación de la pena con fundamento en las circunstancias modificativas de la responsabilidad criminal, con respecto a los delincuentes en general incluso, naturalmente, a los menores de edad penal" (cfr. Las Ideas Jurídicas, cit., p. 59)

${ }^{50}$ Cfr. LEWIS-SHORT, A Latin Dictionary, Oxford, 1980, s. v. recido: "to fall back, return", p. 1531.

51 En el ius novum, a propósito de la aplicabilidad de la abolición general, se establece: remissionem veniae crimine nisi semel commissa non habeant (cfr. C. Th. 9, 38) o sea que el perdón es concedido a quien no ha sido condenado antes por otros delitos. Este principio se manifiesta en diversas épocas: Arcadio y Honorio -siglo $\mathrm{V}_{\text {_: }}$ indignum est humanitate qui post damnationam commissit in 
en ciertos delitos -en el hurto especialmente- una considerable agravación de la pena ${ }^{52}$.

Así las cosas, la insistencia en delinquir era considerada como causa suficiente para aumentar la pena. Como afirma Tomás y Valiente ${ }^{53}$ "No es éste un problema teórico que exija puntualizaciones de entronque filosófico-escolástico, y por ello es cuestión relativamente poco o nada atendida por los Doctores y los penalistas castellanos". Se trata, ante todo, de un problema práctico: el de que hay delitos tan generalizados que muchos ciudadanos los cometen no una sino varias veces; o tan profesionales que hay quienes hacen de ello su modus vivendi. La reincidencia es enfocada siempre en relación con un mismo delito, de ahí que sea en relación con los delitos por ofensas a la divinidad perjurios, blasfemias menores... ${ }^{54} \mathrm{o}$ contra la propiedad -hurtos, robos- donde de un modo más constante las leyes imponen penas más graves a quienes las perpetran reiteradamente ${ }^{55}$. En febrero de 1734, Felipe V imponía la pena de muerte para todo aquel mayor de diecisiete años a quien se probara "haber robado a otro" en la Corte o en las cinco leguas de su Rastro, "ya sea entrando en las casas, o acometiéndose en las calles y caminos, ya con armas o sin ellas, solo o acompañado, y aunque no se siga herida o muerte en la execución del

legem (C. Th. 9, 38). Más textos en C. FERRINI, Diritto Penale, cit., pp. 131 ss. Otras veces la reincidencia -en cuanto indicio de un propósito malévolo- hace que si el hecho fue primero objeto de medidas meramente disciplinarias o de policía se convierta en objeto de verdadera y propia pena. El monge que abandona de nuevo la clausura, no obstante la coerción de su primera deserción, es encarcelado por el gobernador de su provincia y condenado a la pena de trabajos forzados (Nov. 123, c. 42). Los autores de desórdenes, manifestaciones y tumultos son castigados, por primera vez, con sanciones policiales; en caso de reincidencia se les condena con verdaderas penas- fustigatio [sobre ésta poena vid., nuestro: "Algunas Observaciones en torno a la verberatio", en Revue Internationale des Droits de l'Antiquité (Bruselas, 2011) p. 147 ss. ], encarcelamiento o deportatio in insulam (P. S. 5, 21, 1). Probablemente se refieren a la reincidencia los fragmentos que castigan con la pena de muerte a los autores de violencia o de rapina que frecuentemente (saepius) habían cometido el delito.

52 En España, en el Fuero de Caparroso, dado por el rey de Navarra Pedro Sánchez en 1102, se dispone que el que habiéndose probado que ha robado tres veces sobre la cuarta sea ahorcado. Otros fueros contienen análoga disposición. Este rigor se mantiene en siglos posteriores, en el siglo XVII " por el tercer hurto... y aunque este caso no está determinado por derecho, por la general costumbre se les da pena de muerte, son ahorcados", escribe FRANCISCO DE LA PRADILLA BARNUEVO, Tratado y suma de todas las leyes penales, Sevilla, 1613, p. 40; todavía a fines del siglo XVIII, según noticia de ELIZONDO, Práctica Universal forense de los Tribunales superiores de España y de las Indias I, Madrid, 1784, p. 299, se imponía igual pena al culpable en caso del tercer huerto: "mediante la costumbre -dice-de ser ahorcado".

${ }^{53}$ TOMÁS Y VALIENTE, El Derecho Penal, cit., p. 343.

${ }^{54}$ En consecuencia, al que profiere ciertos "votos" o "juramentos", por la primera vez que se le procesare se le castigaba a un mes de cárcel, pero por la tercera vez se le penaba a que se le "enclave la lengua" y a seis años de galeras (NR VIII, 4, 5 y NR VIII, 4, 7).

55 Tanto los Austrias como los Borbones persiguieron dura y casi obsesivamente los hurtos cometidos en la Corte agravando las penas de la legislación anterior (vid., para una exhaustiva exposición de la normativa en punto a esta cuestión: TOMÁS Y VALIENTE, El Derecho Penal, cit., p.252 ss. 
delito", y la misma pena imponía a los cómplices ${ }^{56}$. El primer rey Borbón justificaba tan expeditiva medida por la ineficacia de las leyes vigentes y por su benignidad. Ante la ausencia de claridad de la ley en su tipificación de los delitos -no distinguía el hurto del robo, imponía idéntica penal capital a los autores que a los cómplices- la Sala de Alcaldes pidió aclaraciones que fueron desoídas por el rey calificándolas de "una mal entendida compasión" ${ }^{57}$.

Esta Pragmática Sanción, en su redacción primigenia de 1734, fue defendida sin ambages por Feijoo, lo que le valió una dura crítica de su censor el franciscano Fray Francisco Folch de Cardona ${ }^{58}$ quien -con rotundidad-afirma:

El día veinte y cinco de febrero de 1734 se publicó en Madrid una Pragmática Sanción y Ley, en que el Católico Monarca D. Felipe $\mathrm{V}$ resuelvo: Que a cualquiera persona, que teniendo diecisiete años cumplidos, dentro de mi Corte, y en las cinco leguas de su Rastro y Distrito, le fuera probado haber robado a otro, ya que sea entrando en las casas o acometiéndole en las calles, se le deba imponer pena capital". El censor apostilla: "Luego no faltará un Juez a su ministerio, condenando a pena capital por un hurto simple, o solo. Parece buena la consecuencia que cualquiera Lógico deberá admitir. Mas respondo que la ilación no es buena, siendo verdadero el antecedente. De una ley promulgada, o renovada con justicia, que manda se exponga al último suplicio a cualquiera persona, que probar en haber robado a otro, no le condenará el Juez por un hurto simple, o solo, si mira bien, y premedita las cláusulas del Decreto. Motivó el soberano su resolución justísima diciendo: "Por cuanto reconocimiento, con lastimosa experiencia, la REITERACIÓN [sic., con mayúsculas, en el original] con que se cometen en la mi Corte, y caminos inmediatos, y públicos de ella los delitos de hurto y violencias; enterado de que igual desenfreno puede motivarse de la Benignidad con que se ha practicado lo dispuesto por algunas leyes del Reino". El hurto, acompañado de las circunstancias que su Majestad expresa, no es solo como entiende el Maestro citado, ni simple, con que se explican los Jurisconsultos, siendo al intento sinónimo, los términos. Hurto simple, o solo, se distingue del hurto curcunstanciado o cualificado. Mira el primero a solo el daño, que ocasiona en cuatro, o más reales que usurpa, sin otra circunstancia agravante, o que mude especie. El segundo atiende al hurto, vestido de una o muchas circunstancias: la frecuencia de hurtos, que se experimenta; la dignidad del Lugar en que se comete el delito; la persona que se

${ }^{56}$ NOR., XII, 14, 3.

57 Ibid. XII, 14, 5 donde el rey, con rotundidad dice: "que todo hurto calificado o no de poca o de mucha cantidad, debe estar sujeto a la pena de la Pragmática".

58 "Aprobación del Rmo. P. M. Fr. Francisco Folch de Cardona, Colegial Mayor que fue de Alcalá, etc." $\mathrm{Al}$ T. VI del TCU, X. 
ultraja; el invadir, determinado a vulnerar, o quitar la vida si resiste, y otras a este modo. De la jerarquía segunda (m de la primera) son los delitos que su Majestad dispone se paguen con la vida. La reiteración de semejante delito es mucha circunstancia, su Corte y caminos inmediatos deben asegurar los bienes temporales a sus dueños. La menteria, ya jocosa, ya oficiosa, por sí sola a nadie daña, nos dice el Rmo. Al Discurso nono; pero la impunidad o frecuencia con que se miente, es muy perjudicial al público, porque priva al común de los hombres de un bien muy apreciable. ¿Qué diremos de la frecuencia del hurtar? Un hurto simkple, o solo, es un perjuiucio de bienes de inferior orden a los de vida, y honra; mas si se desordenan los hombres reiterando a cada paso y casa la rapiña, pida la seguridad pública, la paz común, e incorregibilidad de los mortales, se apliquen cáusticos, no sea que de la impunidad se sigan más perjudiciales excesos ${ }^{59}$.

La opinión de Fray Francisco Folch fue mucho más crítica que la de Feijoo respecto de la tipificación del delito de hurto en la Corte y sus aledaños y contribuyó a la derogación de la durísima pragmática de 1734 y su sustitución por la más benigna de $1744^{60}$. Sin duda, Felipe V tuvo muy en cuenta para esta mutación de criterio que la inmensa mayoría de los hurtos cortesanos eran cometidos por profesionales; y es que entre otros móviles más poderosos que les impulsaban a delinquir, la misma ley penal casi incitaba a reincidir en estos delitos. En efecto, siendo la pena ordinaria para el hurto no cualificado la de azotes y destierro, el ladrón "agotaba una ciudad" cuando recibía una pena, pero se marchaba a otra huyendo de la posible futura apreciación de reincidencia, pues siendo desconocido en la segunda ciudad, no era fácil que se le tuvieran en cuenta los hurtos cometidos en otras ${ }^{61}$. Es este uno de tantos pro-

${ }^{59}$ Ibid. [XLI-XLII].

${ }^{60}$ Los Alcaldes de Casa y Corte propusieron en 1744 a Felipe V como forma de mitigar la dureza de la pragmática de 1734 que a los autores de hurtos simples se les penase no a muerte, sino a doscientos azotes y diez años de galeras; y al que delinquiera por vez primera "el verdugo los marcase las espaldas con un hierro ardiendo, hecho en figura de una L, para que si después volviese a incurrir en igual detestable delito, tuviese ya hecha la prueba de haberle cometido antecedentemente" [cfr. NOR., XII, 14,6]. Con todo, Felipe V se negó a utilizar este sistema de prueba de la reincidencia resolviendo que "las penas de los hurtos simples sean arbitrarias, según y como la Sala regulare la qualidad del hurto, teniendo presente para ello la repetición o reincidencia, el valor de lo que se regule del robo, la calidad de la persona a quien se robó, y la del delinqüente, con lo demás que se haya prevenido por el Derecho, no habiéndose conformado con los otros puntos que la Sala expuso en su citada representación". La rúbrica de la Ley VI quedó redactada, en consecuencia, de este modo: "Imposición de penas arbitrarias en los hurtos simples, según la calidad de las personas y circunstancias de ellos".

61 TOMÁS Y VALIENTE, El Derecho Penal, cit., p. 345. Mateo Alemán opinaba que tal disposición legal equivalía a decir al ladrón: "Amigo, ya de aquí te aprovechaste como pudiste y te holgaste a nuestra costa, otro poquito a otro cabo; déjanos a nosotros y pásate a robar a nuestro vecino". Y así era posible, como el mismo autor decía que hubiera "ladrones dichosos que mueren de 
blemas en que demuestra su impotencia el Estado puesto que, si bien se evitaba ciertamente la aplicación de un medio nada humanitario para conocer los antecedentes delictivos, también es cierto que se dejaba prácticamente impune la reincidencia y profesionalidad en materia de hurtos y robos.

Así las cosas, la razón de ser de la agravante de reincidencia ha sido sumamente discutida por los penalistas contemporáneos ya que, en principio, viene a contradecir el punto de vista del purismo clásico, para el que cada delito es una violación del orden jurídico que la pena restablece en su integridad, saldando con ella el culpable la deuda contraída con la sociedad. En consecuencia, el hacer revivir efectos agravatorios por hechos pasados y saldados, vendría a contradecir la máxima del non bis in idem computándose doblemente una misma conducta. Incluso, por algunos se llegó a considerar la reincidencia más bien como título de atenuación, al delatar en el sujeto una acendrada tendencia al mal que demostraba una disminución de su voluntad y, por ende, de su imputabilidad. Para tales doctrinarios, el hecho de computarse como agravante -como venía haciéndose en el Derecho desde tiempo inmemorialera debido a consideraciones pragmáticas de represión inconciliables con los dictados de la ciencia jurídica pura ${ }^{62}$.

El positivismo, al menospreciar como entelequias estas disquisiciones escolásticas y poner el acento sobre la peligrosidad del individuo y la defensa social, no tuvo inconveniente alguno en aceptar la virtualidad agravatoria de la reincidencia, si bien exigió que la misma fuese índice de una mayor capacidad criminal del sujeto sobre la base del estudio de su personalidad más que de los expedientes de antecedentes penales ${ }^{63}$.Pero no esto último no se quiere admitir por dos órdenes de razones; primero, porque significaría una ruptura con el Derecho penal de culpabilidad; segundo, porque implicaría una presunción iuris et de iure en el sentido de que siempre que se produjese la reincidencia había que afirmar también una mayor peligrosidad y esto, según se dice, no es cierto, pues puede darse aquella y no necesariamente esta última ${ }^{64}$. En consecuencia, el Código Penal de 1995 suprimió la "reincidencia genérica", denominada "reiteración" antes de la reforma de 1983, que no exigía analogía ni ninguna otra relación cualitativa entre la anterior y la actual infracción, sino sólo que la condena anterior lo fuera por delito a que la ley señalara igual o mayor pena, o por dos o más delitos a que la ley señalare pena menor. Por otra parte, la reforma de 1983 había suprimido ya la "multirreincidencia", que permitió la imposición de la pena superior en grado a la señalada al delito (única

viejos" [cfr. MATEO ALEMÁN, Aventuras y vida de Guzmán de Alfarache, atalaya de la vida humana (cito por la ed. de Madrid, 1846), II, 1, 8, p. 285 y I, 2, 6, p. 227, respectivamente].

62 Amplia exposición del status quaestionis en S. MIR PUIG, La reincidencia en el Código Penal, Barcelona, 1974, p. 8-13.

${ }^{63}$ M. COBO DEL ROSAL-T. VIVES ANTÓN, Derecho Penal. Parte General, Valencia, 1999, p. 900.

64 G. RODRÍGUEZ MOURULLO, Derecho Penal. Parte General I, Madrid, 1977, p. 743. 
circunstancia en que ello era posible). La evolución legislativa mencionada supuso una tendencia a limitar los efectos agravatorios de la reincidencia ${ }^{65}$.

En el Derecho Romano no era desconocido el concepto de las atenuantes genéricas referidas sobre todo a la conducta del delincuente antes y después de la comisión del delito. Así, en D. 49, 16, 2 pr. Se dice: habetur... ratio... et anteactae vitae y en ibid. 2, 1 se mitiga la pena del desertor si fuerit ultro rever$s u s^{66}$. Esta concepción se transmite a los penalistas hispanos del Antiguo Régimen como Antonio de la Peña que entre las circunstancias atenuadoras de la gravedad de la acción delictiva y por ello suficientes para disminuir la pena al delincuente aludía, entre otras, a la buena fama del reo ${ }^{67}$. Por su parte, Castillo de Bovadilla se refería a muy diversas circunstancias -con o sin apoyo legal expreso- entre las que incluía las referentes a la persona del delincuente ${ }^{68}$. A esta línea se adscribe nuestro Feijoo quien apunta a este respecto:

Los motivos justos para minorar la pena en varios casos son muchos. Los méritos antecedentes del reo, su utilidad para la República, su conocida ignorancia, o inadvertencia, que la moderación de la pena fructifique al pueblo o al Estado, etcétera. Aquel grande Héroe Asturiano Pedro Menéndez de Avilés, Adelantado de la Florida, en varias ocasiones obró en materias de suma importancia para el Estado contra las órdenes, que le había dado el Rey, y un Rey tan celoso de su autoridad como Felipe II se las perdonó todas (...) debido a sus esclarecidos méritos. Fue el Príncipe clemente de este modo de proceder; y sería inicuo, cruel, y feroz por muchos capítulos, si atendiese para el castigo a la ley común. Perdería el Estado un hombre utilísimo, quedarían sin premio alguno unos méritos excelentes; ocasionaríanse con tan funesto ejemplar grandes pérdidas a la República... ${ }^{69}$.

En la práctica solía alegarse también la "rusticidad" del reo, su ignorancia o "pocas luces" como atenuante, entendiéndose que su escaso conocimiento impidió al justiciable detenerse a tiempo en su acción, o que por su poca inteligencia no se percató de que incurría en delito ${ }^{70}$. Dado el carácter vago, abierto y propicio a la interpretación extensiva de estas enumeraciones,

${ }^{65}$ S. MIR PUIG, Derecho Penal. Parte General ${ }^{7}$ (Barcelona, 2004).

66 C. FERRINI, Diritto Penale, cit, p. 131.

67 A. DE LA PEÑA, Tratado muy provechoso, útil y necesario de los juezes y orden de los juicios y penas criminales (BN, Ms. 6379, cap. XII). A pesar de su importancia el texto sigue sin publicar.

68 J. CASTILLO DE BOVADILLA, Política para Corregidores y señores de vasallos II, Amberes, 1750, p. 262-264.

69 FEIJOO, Paradoja Tercera: "Lo que se llama clemencia de Príncipes y Magistrados, perniciosa a los pueblos", en TCU, VI, p. 12.

70 "Cartas de algunos Padres de la Compañía de Jesús, sobre los sucesos de la monarquía entre los años 1634 y 1648", en el Memorial Histórico Español, tomo XVIII, p. 160. 
no es de extrañar su rechazo por la jurisprudencia desde la lejana Sentencia del Tribunal Supremo de 19 de marzo de 1871.

\section{CONCLUSIONES}

La falta de fiabilidad de la prueba testifical proviene no solo de la decadencia de los principios éticos, sino también del no respeto por la judicatura del requisito de la inmediación en la toma de declaraciones y la no aplicación del tipo delictivo del falso testimonio. La circunstancia de la edad debe regirse por el moderno derecho penal de autor que la fija caso por caso.

* Recebido em 10 dez. 2015. 